\title{
Deformation and rupture of thin steel plates due to cumulative loading from underwater shock and bubble collapse ${ }^{1}$
}

\author{
Julian J. Lee ${ }^{\mathrm{a}, *}$, Malcolm J. Smith ${ }^{\mathrm{b}}$, James Huang ${ }^{\mathrm{c}}$ and Geoffrey T. Paulgaard ${ }^{\mathrm{d}}$ \\ ${ }^{a}$ Defence Research and Development Canada - Suffield, Suffield, AB, Canada \\ ${ }^{\mathrm{b}}$ Defence Research and Development Canada - Atlantic, Dartmouth, NS, Canada \\ ${ }^{\mathrm{c}}$ Director Maritime Ship Support, Ottawa, ON, Canada \\ ${ }^{\mathrm{d}}$ Amtech Aeronautical Ltd. Medicine Hat, AB, Canada
}

Received 4 June 2009

Revised 25 November 2009

\begin{abstract}
The damage sustained by rigidly-clamped square steel plates when subjected to close-proximity underwater explosions has been investigated. The test specimens consisted of plates $0.76 \mathrm{~mm}$ and $1.21 \mathrm{~mm}$ thick made of either ASTM A1008 mild steel or $350 \mathrm{WT}$ structural-grade steel with a low-temperature notch-toughness requirement. The explosively-loaded area of the plates was square, with dimensions of $254 \mathrm{~mm} \times 254 \mathrm{~mm}$. High-explosive charges from $1.1 \mathrm{~g}$ to $50 \mathrm{~g}$ were used at different standoff distances to obtain different shock strengths and bubble collapse intensities. Although the main impulsive load on the plate was due to the shock impact, because the standoff distances were less than twice the maximum free-field bubble radius, a strong interaction between the detonation product bubble and the target plate caused a rapid water jet to impinge on the plate, resulting in additional loading and damage. As a result, four main regimes of loading and damage were identified: a) holing/petaling due to shock loading, b) edge tearing due to shock loading only, c) edge tearing due to the cumulative loading from shock and bubble collapse, and d) large deformation due to shock and bubble collapse loading. The damage mechanisms and dynamic response of the plates were measured using dynamic displacement sensors, pressure gauges, and high-speed video. A fracture analysis was performed on the damaged plates to analyze the mechanisms of failure. Finally, finite-element analysis using a failure criterion based on normalized shear stress and effective strain has been used to examine the failure limits.
\end{abstract}

\section{Introduction}

The current threat of terrorist attacks on in-port vessels has prompted detailed research into structural damage from close-proximity underwater charges. In the current preliminary study, the detailed damage mechanisms in thin target plates caused by explosions of close-proximity underwater charges were investigated. In the near-field regimes, shock loading, bubble collapse jetting, plate response, and cavitation all play an important role in the damage mechanisms.

For underwater explosive charges near a rigid structure where the standoff distance is less than twice the maximum free-field bubble radius, the loading consists of a strong shock wave followed much later by an impinging water jet resulting from the collapse of the detonation product bubble. Using twin charges to simulate a rigid wall, Lee et al. [1] showed that close-proximity charges can produce a complex shock interaction comprising several localized

\footnotetext{
${ }^{1}$ Presented at the 79th Shock and Vibration Symposium.

*Corresponding author. E-mail: Julian.lee@drdc-rddc.gc.ca.
} 
phenomena such as Mach reflection and rarefaction waves from the product bubble. In addition, the focused water jet from the bubble collapse was found to apply a much higher impulse than the shock to a localized area in spite of the much smaller peak pressure. The bubble collapse phenomenon has been studied in more detail by Klaseboer et al. [2] who examined the complex flow field and bubble dynamics associated with the collapse through both experiments and simulations. In addition to these phenomena, hull cavitation from shock-induced motion of the structure can also cause pressure cut-off, thus reducing the applied impulse [3].

Damage in rigidly-clamped thin plates has been studied extensively for air blast loading situations. Three main modes of damage were originally identified for blast-loaded beams by Opat and Menkes [4]: mode I - large ductile deformation, mode II - tensile tearing and deformation, and mode III - transverse shear; these were first successfully applied to plates by Teeling-Smith and Nurick [5]. Since then, refinements have been made to these modes to account for various stages of partial rupture and interaction between the modes. For example, a subdivision of mode I into modes Ia and Ib was proposed by Nurick et al. [6] to account for partial and complete necking at the clamped edge, and a subdivision of mode II into modes II*, IIa, and IIb was proposed by Nurick and Shave [7] to account for partial rupture at the edge and different regimes of deformation.

These modes of failure also apply to underwater blast loading, and Ramajeyathilagam [8] added mode IIc to describe complete edge tearing combined with a central sheared hole. Underwater charges in contact with thin air-backed plates generally produce a large hole with several petals, as described in experimental and numerical studies by Church et al. [9], Riley et al. [10], and Gregson et al. [11] who each used different modeling approaches to the problem. Slater et al. [12] defined a new set of damage modes (patterns I-VII) which intersect with previouslydefined modes, but introduce additional modes associated with plates having a layer of water on the air-backed side. For example, patterns I and II describe counter-intuitive motion specific to plates with contact charges and a water layer backing to mitigate damage.

With recent advances in algorithms for fluid-structure interactions such as Eulerian-Lagrangian mesh-coupling schemes [2,9,11,13] or Arbitrary Eulerian-Lagrangian (ALE) methods [10], damage of underwater blast-loaded plates has been modeled with some success. Rupture limits, however, have proven more difficult to predict although various approaches have been tried such as a plastic hinge at the clamped edge combined with a failure strain criterion [6], or a ductile fracture mechanism based on the growth and coalescence of voids [9]. Rudrapatna and Vaziri [14] used a simplified criterion that combines total strain and transverse shear, and had reasonable success at predicting the onset of mode II and III rupture.

The present work constitutes a preliminary investigation of the mechanisms of plate failure in close-proximity to an underwater explosion (UNDEX). Using a simple air-backed thin plate as a responding structure, the failure process has been studied through high-speed video, displacement and pressure measurements, and finite-element analysis. First the loading process from shock and bubble collapse is described through pressure measurements, then the response and damage to the plate is shown through dynamic displacement measurements and post-test analysis of the deformed and ruptured plates. The damage is then classified according to previously established damage modes in the literature, and the type of rupture is confirmed through microscopic fracture analysis. By varying the explosive charge standoff distance, different regimes of loading and damage in the near-field region are examined. Finally, a simplified modeling approach for predicting failure limits is presented for shock-induced failure to help explain the dependence of failure limits on material properties, plate thickness, and charge standoff distance.

\section{Experimental details}

The experiments were conducted at the UNDEX pond facility of Defence Research and Development Canada Suffield. The pond is $50 \mathrm{~m}$ in diameter and $8 \mathrm{~m}$ in depth with a truncated cone shape. The tests were performed on a concrete pad at the bottom of the pond, at a depth between 5-6 $\mathrm{m}$.

The apparatus used for the tests consisted of a steel drum $610 \mathrm{~mm}$ in diameter and $910 \mathrm{~mm}$ in height as shown in Fig. 1. The test plates consisted of square steel plates $457 \mathrm{~mm}$ in dimension and were clamped to the air-tight drum using a square flange (in blue) with twenty-four bolts such that the explosively-loaded area of the plate was a square $254 \mathrm{~mm}$ in dimension. To minimize pull-in slippage of the plate during shock loading, steel retaining pins were placed through the plate at the center of each edge. During the tests, some slippage of 2-5 mm was still observed. 
Table 1

Target plate material properties from Riley et al. [10]

\begin{tabular}{lcccccccc}
\hline & $\rho \mathrm{g}\left(\mathrm{Kg} / \mathrm{m}^{3}\right)$ & $\mathrm{E}(\mathrm{GPa})$ & $\varepsilon_{u l t}$ & $\mathrm{E}_{T}(\mathrm{GPa})$ & $\mathrm{D}(1 / \mathrm{s})$ & $\mathrm{n}$ & $\sigma_{y}(\mathrm{MPa})$ & $\sigma_{u l t}(\mathrm{MPa})$ \\
\hline A1008 & 7850 & 164.3 & 0.37 & 1.562 & 40.4 & 5 & 189.5 & 312.6 \\
350WT & 7850 & 194.4 & 0.18 & 1.455 & 3200 & 5 & 265.1 & 335.8 \\
\hline
\end{tabular}

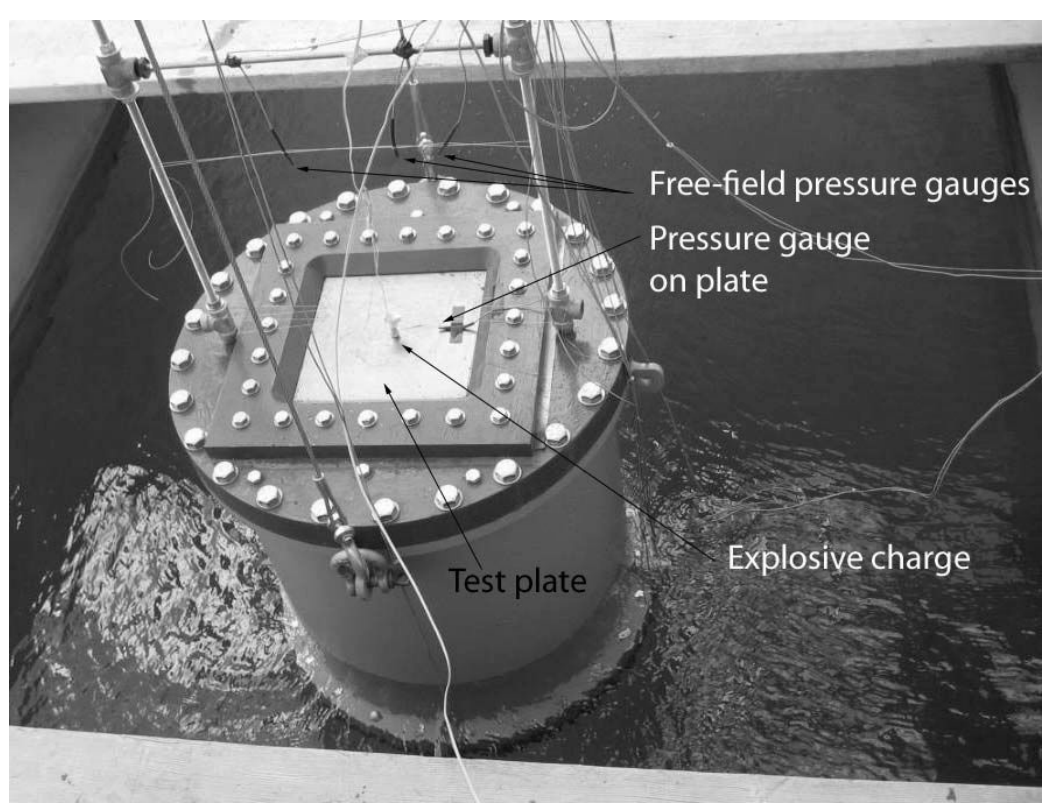

Fig. 1. Apparatus for performing underwater explosion testing of square plates.

The explosive charge was placed at the desired standoff distance above the center of the test plate, and the entire apparatus was lowered into the water to rest on the concrete pad during the test.

The explosive charges consisted of $1.1 \mathrm{~g}, 20 \mathrm{~g}$, or $50 \mathrm{~g}$ of high explosive. The $1.1 \mathrm{~g}$ charges consisted of a Reynolds RP-83 detonator with the tip of the aluminum casing removed so as not to produce fragments that might influence fracture in the experiment. The explosive in the detonator consisted of $91 \%$ RDX with the remaining $9 \%$ binder, and had a density of approximately $1.6 \mathrm{~g} / \mathrm{cc}$. The $20 \mathrm{~g}$ and $50 \mathrm{~g}$ charges consisted of spheres of C4 comprising $91 \%$ RDX and a balance of binders and fuel oil.

The instrumentation consisted of Neptune Sonar TR-2 piezoelectric gauges for pressure measurements, a Microepsilon laser displacement transducer, and a Phantom 7 high-speed video camera for recording underwater images of the explosive event. The free-field pressure was measured a certain distance from the charge, on the side opposite the drum (Fig. 1). Pressure transducers were also placed directly on the surface of the test plate, at locations $38-100 \mathrm{~mm}$ from the center. The displacement transducer was mounted inside the drum, and was positioned to record the dynamic deflection at a point $38 \mathrm{~mm}$ from the center of the plate, towards the middle of one of the edges. The camera was typically operated at a framing rate of 3000-6000 frames/sec depending on the natural lighting conditions which varied with the direction of the sun and the water clarity.

The steel plates were made of either A1008 mild steel, or 350WT steel with a low-temperature notch-toughness requirement. The material properties for the two types of steel were obtained through quasi-static tensile tests and open literature, and are shown in Table 1, where $\rho$ is the density, E is the modulus of elasticity, $\varepsilon_{u l t}$ is the failure strain, $\mathrm{E}_{T}$ is the tangential modulus, $\mathrm{D}$ and $\mathrm{n}$ are the Cowper-Symonds strain rate parameters, $\sigma_{y}$ is the tensile yield strength and $\sigma_{u l t}$ is the tensile ultimate strength. Two thicknesses of mild steel were used: $1.21 \mathrm{~mm}$ (18 gauge), and $0.76 \mathrm{~mm}$ (22 gauge). For the 350WT steel plates, a single thickness of $1.21 \mathrm{~mm}$ (18 gauge) was used.

A list of the test configurations is shown in Table 2. The standoff distance is given in millimetres from the charge center to the surface of the plate, except in the case of contact charges. The distance is also given in terms of the free-field maximum bubble radius $(\mathrm{Rb})$ of the explosion products estimated from similitude equations [15]. 
Table 2

List of all tests and basic test conditions

\begin{tabular}{|c|c|c|c|c|}
\hline \multirow[t]{2}{*}{ Material } & \multirow[t]{2}{*}{ Thickness (mm) } & \multirow[t]{2}{*}{ Charge (g) } & \multicolumn{2}{|c|}{ Standoff } \\
\hline & & & $(\mathrm{mm})$ & $(\mathrm{Rb})$ \\
\hline A1008 & 0.76 & 1.1 & Contact & Contact \\
\hline A1008 & 0.76 & 1.1 & 164 & 1.06 \\
\hline A1008 & 0.76 & 20 & 198 & 0.50 \\
\hline A1008 & 0.76 & 20 & 249 & 0.63 \\
\hline A1008 & 0.76 & 20 & 337 & 0.85 \\
\hline A1008 & 0.76 & 20 & 419 & 1.06 \\
\hline A1008 & 0.76 & 20 & 455 & 1.15 \\
\hline A1008 & 0.76 & 20 & 495 & 1.25 \\
\hline A1008 & 1.21 & 1.1 & Contact & Contact \\
\hline A1008 & 1.21 & 1.1 & Contact & Contact \\
\hline A1008 & 1.21 & 1.1 & 164 & 0.94 \\
\hline A1008 & 1.21 & 20 & Contact & Contact \\
\hline A1008 & 1.21 & 20 & 25 & 0.06 \\
\hline A1008 & 1.21 & 20 & 60 & 0.15 \\
\hline A1008 & 1.21 & 20 & 99 & 0.25 \\
\hline A1008 & 1.21 & 20 & 150 & 0.38 \\
\hline A1008 & 1.21 & 20 & 210 & 0.53 \\
\hline A1008 & 1.21 & 20 & 297 & 0.75 \\
\hline A1008 & 1.21 & 20 & 337 & 0.85 \\
\hline A1008 & 1.21 & 20 & 348 & 0.88 \\
\hline A1008 & 1.21 & 20 & 419 & 1.06 \\
\hline A1008 & 1.21 & 20 & 629 & 1.59 \\
\hline A1008 & 1.21 & 50 & 269 & 0.50 \\
\hline A1008 & 1.21 & 50 & 403 & 0.75 \\
\hline A1008 & 1.21 & 50 & 569 & 1.06 \\
\hline A1008 & 1.21 & 50 & 711 & 1.32 \\
\hline A1008 & 1.21 & 50 & 741 & 1.38 \\
\hline A1008 & 1.21 & 50 & 806 & 1.50 \\
\hline $350 \mathrm{WT}$ & 1.21 & 1.1 & Contact & Contact \\
\hline $350 \mathrm{WT}$ & 1.21 & 1.1 & 164 & 1.06 \\
\hline $350 \mathrm{WT}$ & 1.21 & 20 & 99 & 0.25 \\
\hline $350 \mathrm{WT}$ & 1.21 & 20 & 198 & 0.50 \\
\hline $350 \mathrm{WT}$ & 1.21 & 20 & 249 & 0.63 \\
\hline $350 \mathrm{WT}$ & 1.21 & 20 & 297 & 0.75 \\
\hline $350 \mathrm{WT}$ & 1.21 & 20 & 396 & 1.00 \\
\hline $350 \mathrm{WT}$ & 1.21 & 20 & 396 & 1.00 \\
\hline $350 \mathrm{WT}$ & 1.21 & 20 & 444 & 1.12 \\
\hline $350 \mathrm{WT}$ & 1.21 & 20 & 594 & 1.50 \\
\hline
\end{tabular}

\section{Results and discussion}

\subsection{Shock and bubble collapse loading}

The shock pressure was recorded both in the free-field far from the plate, and directly on the plate. The free-field pressure histories had a typical sharp rise and exponential-like decay, as shown in Fig. 2a for a $50 \mathrm{~g}$ charge $569 \mathrm{~mm}$ from a 1.21-mm thick A1008 steel plate. In this case, the plate ruptured after the bubble collapse. The free-field pressure was measured at a distance of $816 \mathrm{~mm}$, with a peak pressure of $84 \mathrm{MPa}$, a duration of $\sim 40 \mu \mathrm{s}$, and an impulse of $\sim 3 \mathrm{MPa}-\mathrm{ms}$. Figure $2 \mathrm{~b}$ shows a typical pressure history recorded from a gauge on the plate, $38 \mathrm{~mm}$ from the center. The peak pressure was found to be $47 \mathrm{MPa}$, with a much shorter duration of $\sim 15 \mu$ s and an impulse of $0.22 \mathrm{MPa}-\mathrm{ms}$. The shock impulse was typically reduced by an order of magnitude by the plate motion and cavitation cutoff at the surface.

The detonation bubble collapse onto the plate produced additional loading on the plate, and was also recorded by the pressure gauges. The collapse occurred $25-90 \mathrm{~ms}$ after the arrival of the shock at the plate depending primarily on the charge size and whether plate ruptured or not. A typical bubble collapse pulse measured far from the plate is shown for a $50 \mathrm{~g}$ charge $741 \mathrm{~mm}$ from a $1.21 \mathrm{~mm}$ A1008 steel plate in Fig. 3a. In this case, the plate did not rupture, 


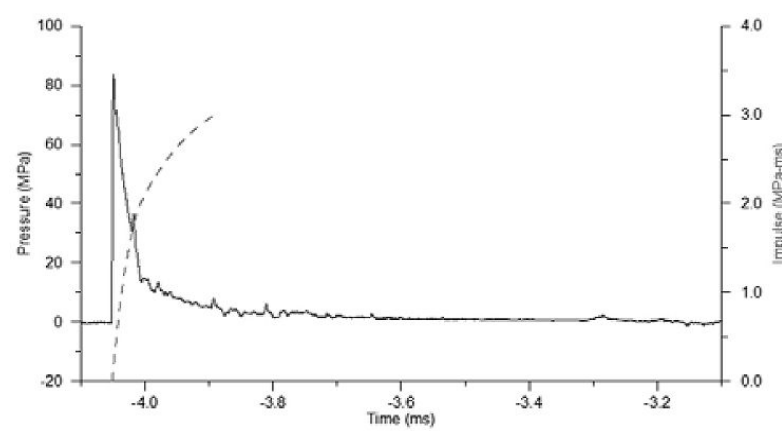

(a)

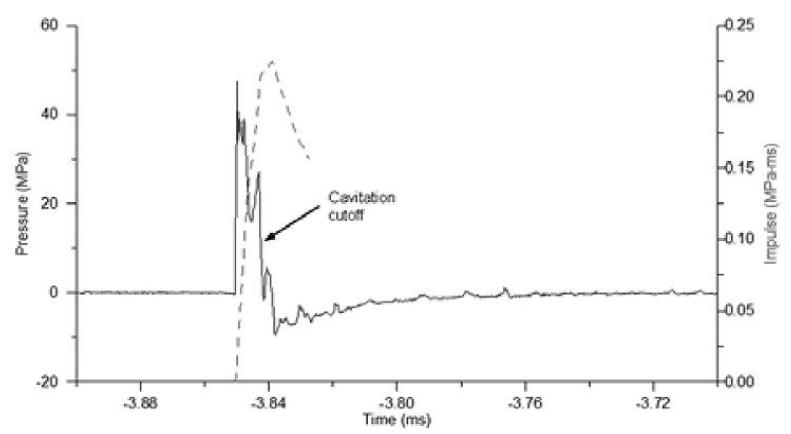

(b)

Fig. 2. Shock pressure histories: a) free-field, b) on plate surface. Dashed lines represent impulse.

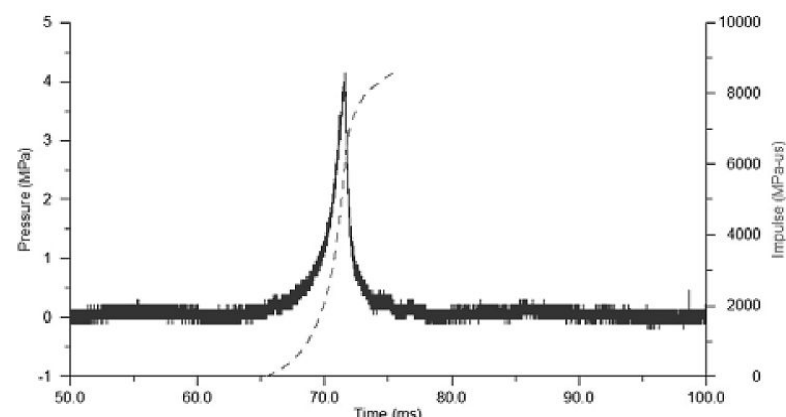

(a)

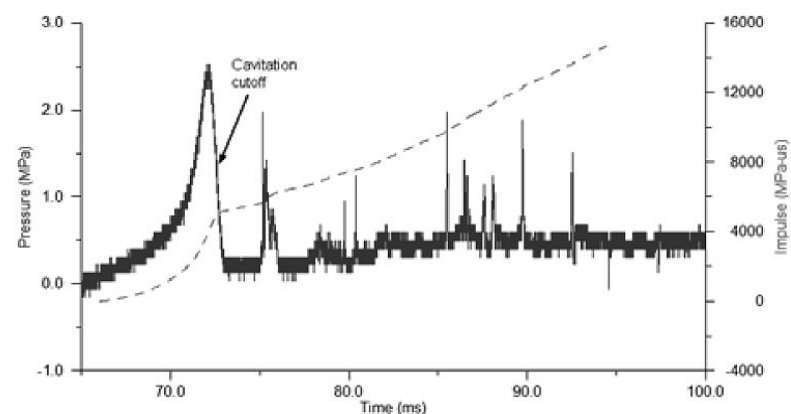

(b)

Fig. 3. Bubble collapse pressure histories: a) free-field, b) on plate surface. Dashed lines represent impulse.

but sustained a permanent deflection of $28 \mathrm{~mm}$ at the mid-point. The pressure measured directly on the plate surface was far more irregular due to cavitation from the bubble jet-induced motion of the plate (Fig. 3b).

\subsection{Plate response and deformation}

The dynamic measurements of the deflection at a point $38 \mathrm{~mm}$ from the center showed a strong response to both the shock and bubble collapse loading. Depending on the charge size, standoff distance, plate thickness, and plate properties, the deformation and failure was dominated by the shock alone, or by both shock and bubble collapse. Figure 4a shows a plate deformation due predominantly to the shock loading. In this case, the charge size was $50 \mathrm{~g}$, the standoff distance was $741 \mathrm{~mm}$, and the plate was a 1.21-mm thick A1008 steel plate. After a strong permanent deflection of $28 \mathrm{~mm}$ caused by the shock, the subsequent impulsive loading $85 \mathrm{~ms}$ later from the bubble collapse produced only a small elastic deflection. For certain cases such as the $1.1 \mathrm{~g}$ charge $164 \mathrm{~mm}$ from a $0.76-\mathrm{mm}$ thick A1008 steel plate shown in Fig. 4b, both the shock loading and the bubble collapse played a significant role in the final permanent deflection. After a shock-induced deflection of $\sim 16 \mathrm{~mm}$, the subsequent bubble collapse $25 \mathrm{~ms}$ later caused an additional deflection to $\sim 23 \mathrm{~mm}$.

The final permanent deformation of the plates in the cases where rupture did not occur were mostly of a common parabolic shape, as can be seen in the deflection profile for a $20 \mathrm{~g}$ charge $594 \mathrm{~mm}(1.50 \mathrm{Rb})$ from a 1.21 -mm thick 350WT steel plate in Fig. 5a, where the deflection $\delta$ is normalized to the maximum deflection $\delta_{m}$, plotted against the distance " $r$ " from the center of the plate normalized to the distance from the center to the middle of the edge "a". In this case, the maximum deflection is $20 \mathrm{~mm}$. For shorter standoff distances, a localized bulge near the charge resulted in a slightly different deformation profile having an inflection point, as in the profile for a $20 \mathrm{~g}$ charge at a $337 \mathrm{~mm}(0.85 \mathrm{Rb})$ standoff from a 1.21-mm thick A1008 steel plate shown in Fig. 5b. In this case, the localized bulge was likely caused by the focused bubble jet, and the maximum deflection was $57 \mathrm{~mm}$. 


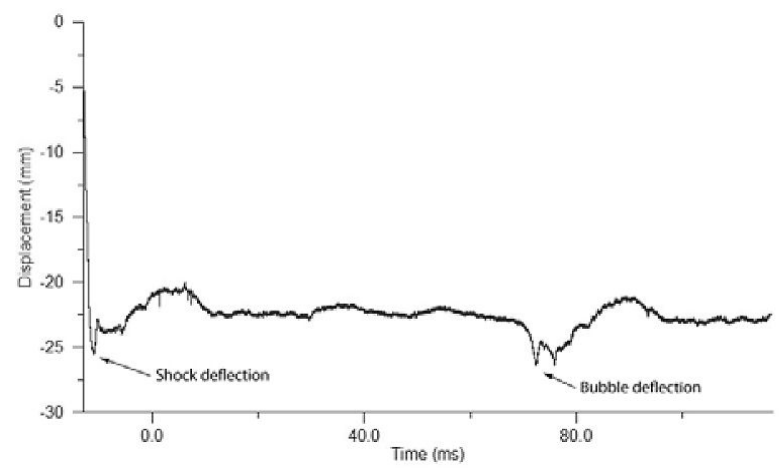

(a)

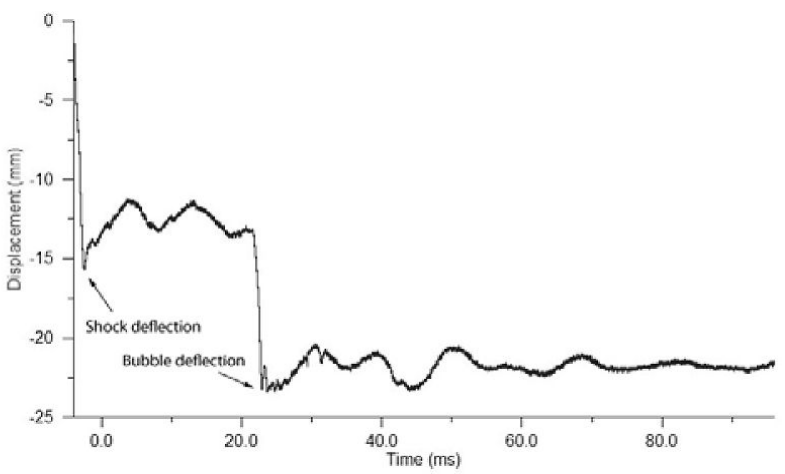

(b)

Fig. 4. Dynamic mid-point deflection histories: a) shock-dominated deflection, b) deflection from both shock and bubble collapse.

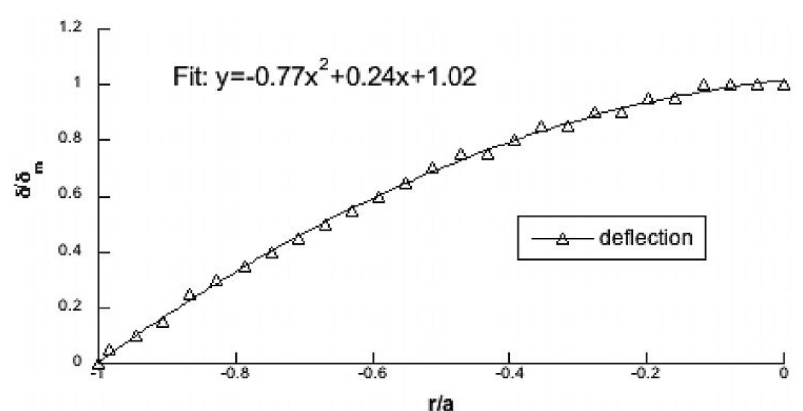

(a)

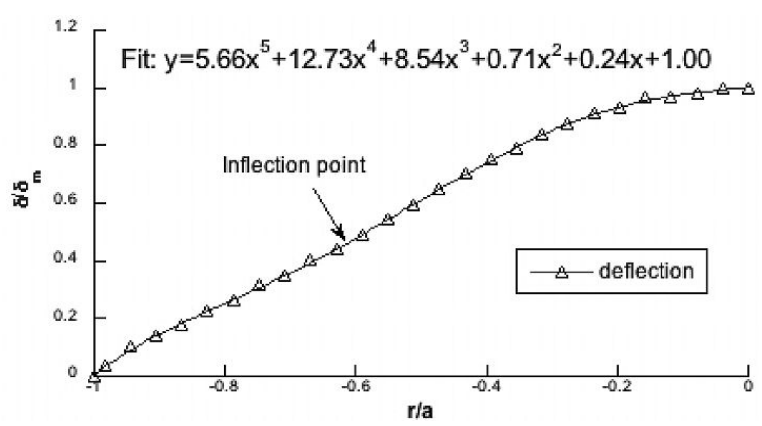

(b)

Fig. 5. Deformation profiles for plates that did not rupture: a) parabolic shape, b) inflection point.

\subsection{Damage modes}

Four main modes of plate damage were observed: large deformation or dishing away from the charge, as shown in Fig. 6a, local holing and petaling as shown in Fig. 6b, partial rupture on three sides as shown in Fig. 6c, and finally rupture on all four sides with the plate plug ejected from the center, as shown in Fig. $6 \mathrm{~d}$. The large deformation mode is analogous to the Mode I described by Teeling-Smith and Nurick [5] and other authors [6-8,12]. The local holing and petaling mode was observed only for contact charges in this study, however the standoff distance at which a transition to a more global plate deformation mode has been studied by Riley et al. [10] for these plates. For the $1.1 \mathrm{~g}$ charges, the transition point was 2.1 to $4.5 \mathrm{~mm}$, depending on the plate material and thickness. For the $20 \mathrm{~g}$ charge, holing failures occurred up to 23-26 mm standoff distances for the A1008 plates, and to 33-35 mm for the 350WT plates. Studies performed by Slater et al. [12] showed that for $1.1 \mathrm{~g}$ charges, a transition from a holing and petaling mode to a large deformation mode occurred at a standoff distance between 2-5 mm for round A653 galvanized plates $1.3 \mathrm{~mm}$ thick. For the other rupture modes observed in this study, no distinction was made between Modes II and III since a microscopic analysis was not performed for all plates. Moreover, additional bending damage was sustained by the central plate plug ejected from the frame, so it was not possible to distinguish Modes IIa and IIb [7].

\subsection{Fracture analysis}

A preliminary fractography analysis of the plates showed a number of microscopic features for the rupture. The plates that sustained edge rupture exhibited a shear instability after some doming deformation of the central portion. A closer analysis was performed for the cases of local holing and petaling, as they exhibited a wider range of fracture mechanisms. 


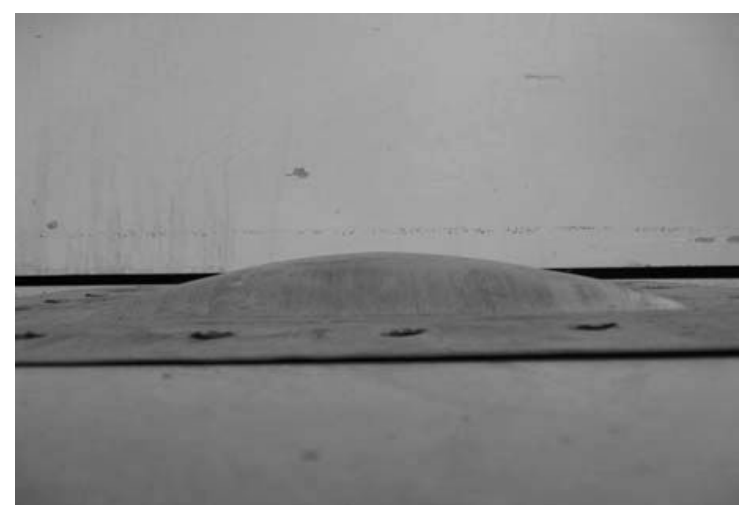

(a)

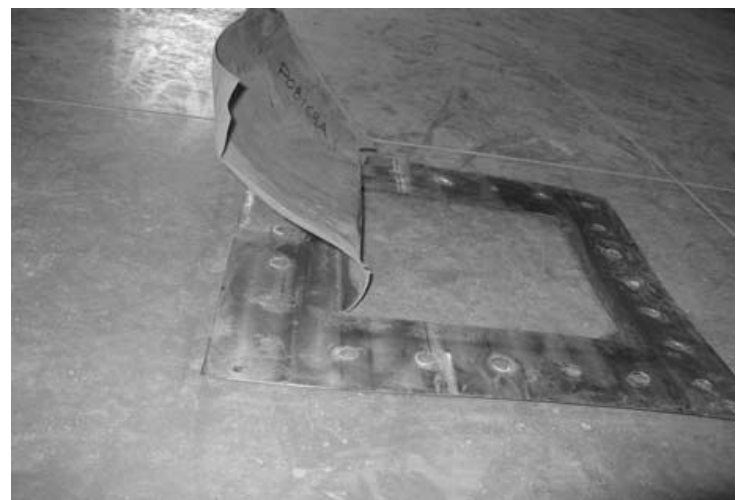

(c)

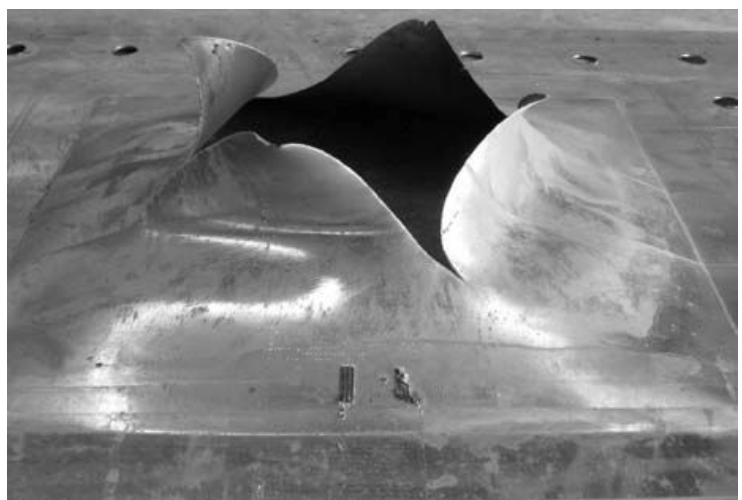

(b)

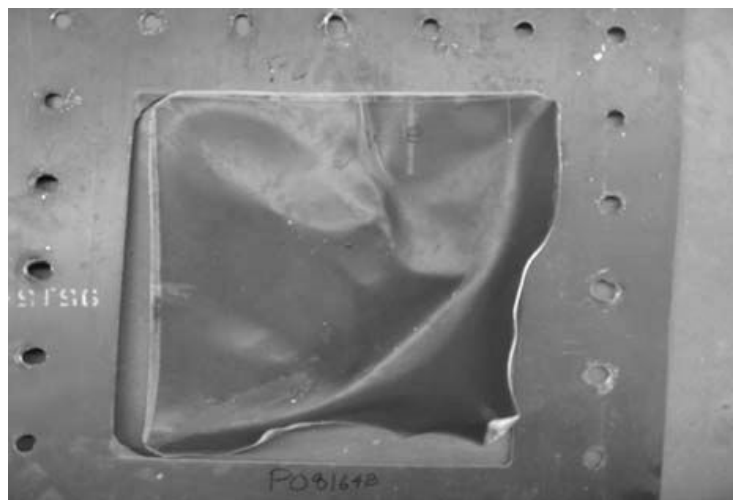

(d)

Fig. 6. Different modes of plate damage: a) deformation, b) holing and petaling, c) partial edge rupture, and d) complete edge rupture.

Figure 7 shows Scanning Electron Microscope (SEM) images of a typical fracture surface of a $1.21 \mathrm{~mm}$ thick A1008 steel plate after holing and petaling from a $1.1 \mathrm{~g}$ contact charge. The shock pressure due to the underwater explosion was from the bottom side of the sample in the images. Delamination can be seen in the sample, as the steel separated at the mid-thickness plane (Fig. 7a). This is likely caused by the centre-line segregation of pearlite phase in the material, which is frequently encountered in this type of steel. The shock wave may have caused fracture of the less ductile pearlite phase in the mid-thickness of the panel, thus delaminating the material. On the air side of the sample, some rubbing marks on the fracture surface can be observed in Fig. 7b, shown as the parallel striations on the micrograph. These marks were probably introduced by a fragment spalling off from the plate. The rest of the fracture surfaces can be characterized by ductile shear (Fig. 7c) and quasi-cleavage (Fig. 7d) fracture mode, each occurring in approximately $90 \%$ and $10 \%$ of the entire area, respectively.

In another test under identical conditions, the fracture was slightly more severe. Local thinning can be observed, indicating plastic deformation prior to fracture (Fig. 8a). Ductile fracture is evident as indicated by the micro void coalescence shown in Fig. 8b. Ductile shear fractures were also observed in the fracture surfaces of the target panel. The present fracture analysis indicates that the primary failure mode of the plates was plastic overloading featuring ductile shear failure.

\subsection{Failure standoff regimes}

The close-proximity underwater explosion loading of the plate is directly related to the charge size and standoff, and to a lesser degree to the plate thickness and properties. For example, near-contact charges produce a very high-pressure, localized load. Charges at larger standoff distances, but still in the near field within two maximum free-field bubble radii, produce loads consisting of the combined effects of the shock and bubble collapse. The 


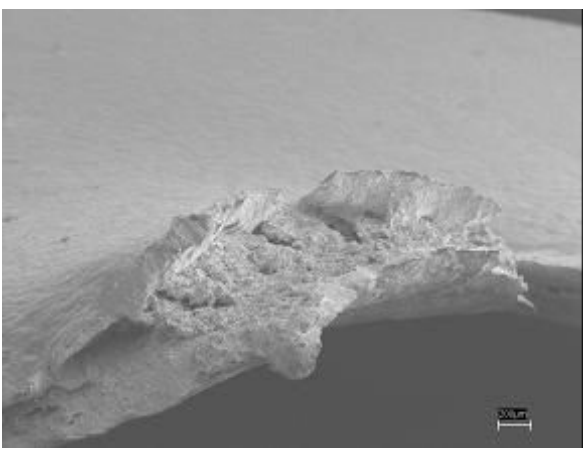

(a)

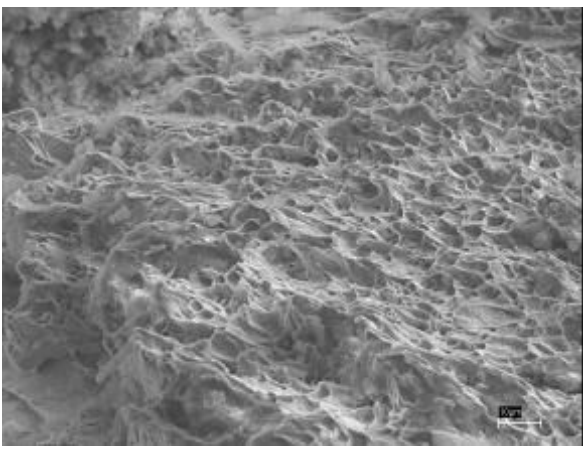

(c)

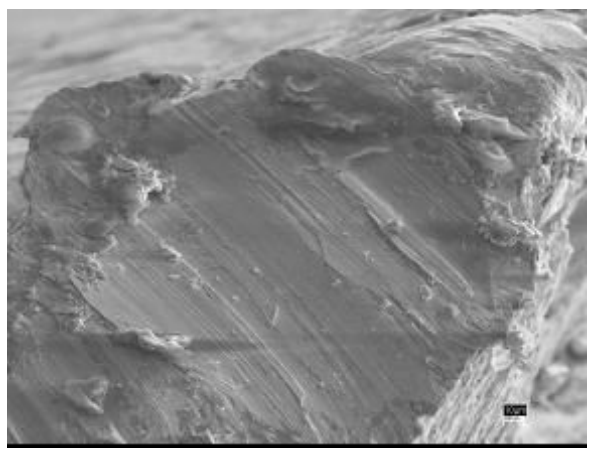

(b)

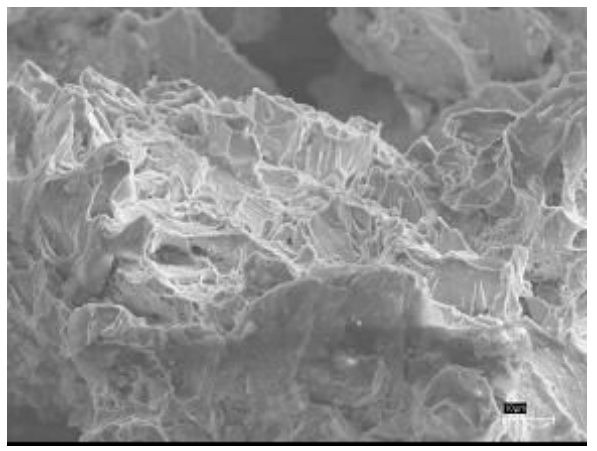

(d)

Fig. 7. Fracture surfaces from a plate displaying local holing and petaling damage: a) delamination, b) rubbing, c) ductile shear, and d) quasi cleavage.

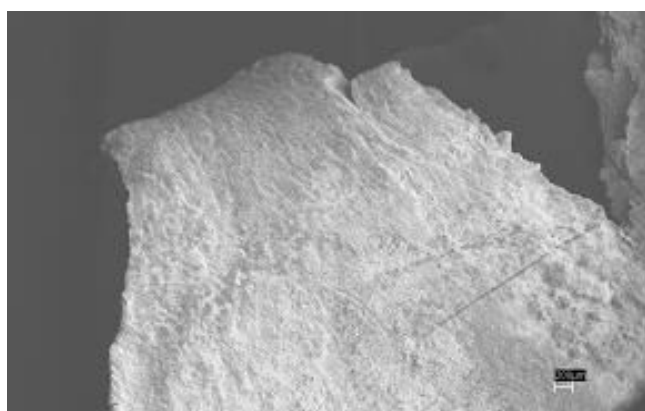

(a)

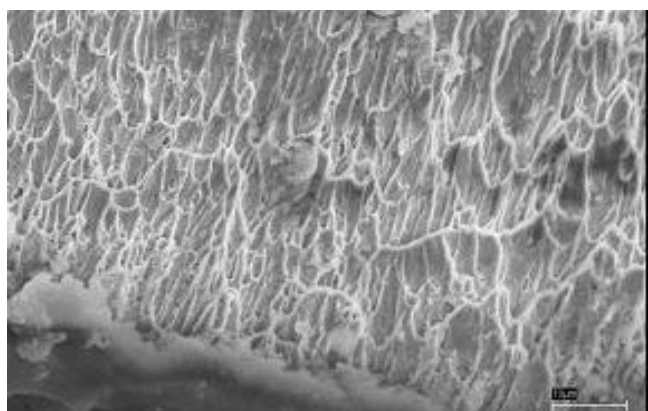

(b)

Fig. 8. Fracture surfaces from a plate displaying local holing and petaling damage: a) thinning, b) void coalescence.

damage modes can be related to the loading by examining the damage as a function of the standoff for a given charge size. Standoff regimes for plate failure can thus be identified as follows for increasing standoff distance:

1. the plates undergo local holing and petaling (near-contact charges),

2. the plates undergo a partial or complete edge rupture due to shock loading alone,

3. the plates undergo a partial or complete edge rupture due to the cumulative loading from both the shock and bubble collapse,

4. the plates undergo large deformation loading due to the cumulative loading from both shock and bubble collapse. 
Table 3

Failure standoff regimes

\begin{tabular}{|c|c|c|c|c|}
\hline Plate specimen & Holing and petaling & Shock rupture & Shock and bubble collapse rupture & Large deformation \\
\hline $0.76 \mathrm{~mm} \mathrm{~A} 1008,20 \mathrm{~g}$ charge & contact & Near-contact to $0.5 \mathrm{Rb}$ & $0.63 \mathrm{Rb}$ to $1.15 \mathrm{Rb}$ & $>1.25 \mathrm{Rb}$ \\
\hline $1.21 \mathrm{~mm} \mathrm{~A} 1008,1.1 \mathrm{~g}$ charge & contact & & & above near-contact \\
\hline $1.21 \mathrm{~mm}$ A $1008,20 \mathrm{~g}$ charge & contact & Near-contact to $0.38 \mathrm{Rb}$ & $0.53 \mathrm{Rb}$ to $0.75 \mathrm{Rb}$ & $>0.85 \mathrm{Rb}$ \\
\hline $1.21 \mathrm{~mm} \mathrm{~A} 1008,50 \mathrm{~g}$ charge & contact & Near-contact to $0.5 \mathrm{Rb}$ & near $1.06 \mathrm{Rb}$ & $>1.32 \mathrm{Rb}$ \\
\hline $1.21 \mathrm{~mm} 350 \mathrm{WT}, 20 \mathrm{~g}$ charge & contact & Near-contact to $0.5 \mathrm{Rb}$ & $0.63 \mathrm{Rb}$ to $1.0 \mathrm{Rb}$ & $>1.12 \mathrm{Rb}$ \\
\hline
\end{tabular}

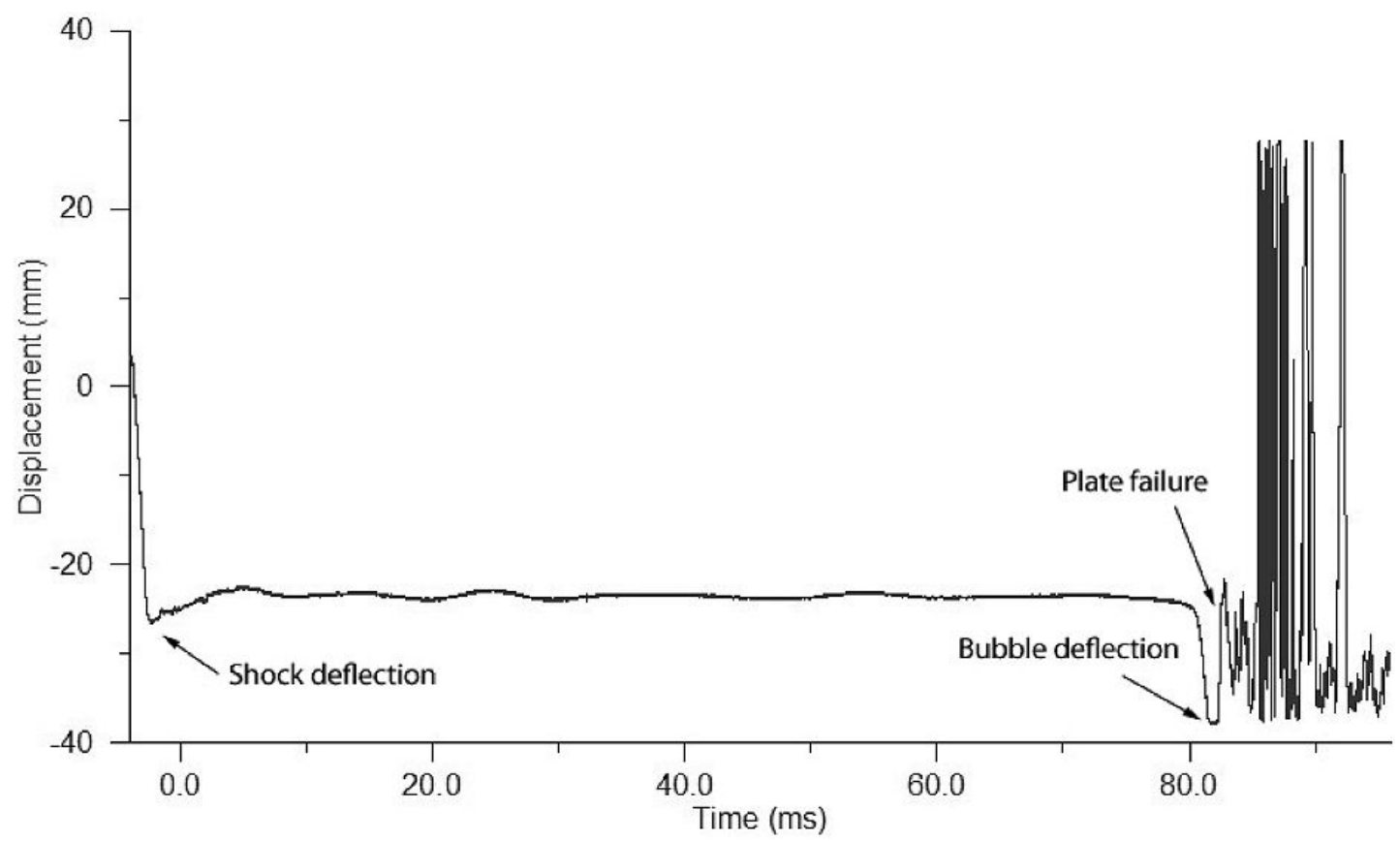

Fig. 9. Dynamic mid-point deflection histories showing plate failure after shock and bubble collapse deflection. The test conditions are a $50 \mathrm{~g}$ charge at a standoff distance of $569 \mathrm{~mm}$ from a $1.21 \mathrm{~mm}$ A1008 steel plate.

At even larger standoff distances, the doming deformation of the plate is expected to be caused by the shock only since the bubble is too far from the plate to collapse on it.

The limit between the shock loading failure and cumulative shock and bubble loading failure can be identified in two ways. The first way is to observe the moment of failure on a displacement gauge, as shown in Fig. 9. After an initial shock deflection, a bubble collapse deflection was observed $84 \mathrm{~ms}$ later. The plate failed $\sim 800 \mu$ s after the bubble collapse deflection. In this test, the displacement gauge sustained impact damage from the flying plate plug. A preferable way of identifying failure due to shock and bubble collapse is to observe an increase in the bubble collapse period when the plate fails from shock loading. For example, if the plate did not fail, or failed only after the bubble collapse, the bubble was found to collapse after a period of $\sim 60 \mathrm{~ms}$ for a $20 \mathrm{~g}$ charge. If the plate failed due to shock loading, venting of the detonation products into the air cavity of the drum apparatus caused the period to increase to $\sim 70 \mathrm{~ms}$. Hence early venting of the bubble due to shock-induced failure increased the bubble collapse period by $8 \%$ to $17 \%$. This increase is consistent with simple models accounting for the product outflow from the bubble [16]. The bubble collapse period was readily observed through high-speed video and pressure gauge signals, and provided a convenient means of identifying the cumulative shock and bubble loading regime.

Based on the four standoff regimes mentioned above, the limits for the plate and charge configurations tested were determined, and are shown in Table 3, where $\mathrm{Rb}$ is the free-field maximum bubble radius. $\mathrm{Rb}$ was calculated using similitude equations [15], and for the charge sizes of $1.1 \mathrm{~g}, 20 \mathrm{~g}$, and $50 \mathrm{~g}$, the values were found to be $155 \mathrm{~mm}$, $398 \mathrm{~mm}$, and $537 \mathrm{~mm}$ respectively. The tests with 0.76-mm thick A1008 steel plates showed a shift in the regimes 
towards larger standoff distances as compared to $1.21 \mathrm{~mm}$ plates, while the $1.21 \mathrm{~mm} 350 \mathrm{WT}$ plates also showed a shift towards large standoff distances compared to their A1008 steel plate counterpart.

\subsection{Failure limit models}

To further examine the behaviour of the failure regimes, Finite Element Analysis (FEA) was performed using TRIDENT [17]. For this analysis, only the shock-induced response and failure were considered. To address the non-planarity of a close-proximity charge [1], a simplified shock model was developed using similitude equations for pressure [15] and ray-tracing to implement the geometrical features of the charge and plate. Only regular reflection was assumed for the shock, and Taylor's reflection model for a finite-thickness plate [3] was used to account for the plate motion. Cavitation cutoff was activated when the reflected shock pressure decreased below the hydrostatic pressure. Comparisons of this simplified shock loading model with a first-order Doubly Asymptotic Approximation (DAA1) method in the USA code [18] showed very similar results for early-time response of the plate.

Quarter models of the target plates were used with symmetry conditions along two central axes. The plates were meshed with plate/shell elements with additional refinement near the edges of the plate where failure was observed in the majority of the test cases. Modelling of the holing/petaling failure mode has been conducted under a separate study [10]. Two boundary conditions were used at the plate edges: (1) fully clamped, and (2) constraint of normal displacement and rotation with no constraint of the membrane deformation. The first of these was found to produce more realistic deformations, although neither condition fully realizes the actual restraint that exist.

Geometric and material nonlinearity was incorporated in the plate response predictions. An elasto-plastic material model with isotropic hardening was used and strain rate effects were included through the Cowper-Symonds relation. Failure (rupture) of the target plates was predicted using the Linear Interaction Criterion (LIC) and Quadratic Interaction Criterion (QIC) $[8,14]$, in which failure is assumed to be an interaction between in-plane membrane strain and through-thickness shear stress ratios. The failure rupture ratios are defined as:

$$
\begin{gathered}
L I C=\frac{\varepsilon_{p}}{\varepsilon_{u l t}}+\frac{\max \left(\left|\tau_{x z}\right|,\left|\tau_{y z}\right|\right)}{\tau_{\text {dyn-ult }}}, \\
\text { QIC }=\left[\frac{\varepsilon_{p}}{\varepsilon_{u l t}}\right]^{2}+\left[\frac{\left|\tau_{x z}\right|,\left|\tau_{y z}\right|}{\tau_{\text {dyn-ult }}}\right]^{2},
\end{gathered}
$$

where $\varepsilon_{p}, \varepsilon_{u l t}$ are the plastic and failure strain of the material, $\tau_{x z}, \tau_{y z}$ are the components of through-thickness shear stress in the plate, and $\tau_{d y n-u l t}$ is the ultimate dynamic shear stress, which is approximated as:

$$
\tau_{\text {dyn-ult }} \approx \frac{\sigma_{u l t}}{\sqrt{3}}\left(1+\left(\frac{|\dot{\varepsilon}|}{D}\right)^{1 / n}\right)
$$

where $\sigma_{u l t}$ is the static ultimate strength of the material, $\dot{\varepsilon}$ is the strain rate, and both $D$ and $n$ are Cowper-Symonds parameters accounting for the effect of strain rate on flow stress.

Figure 10 gives results of the LIC and QIC methods, in which failure is assumed to occur for rupture ratios equal to one. For both criteria, the shock failure limit obtained in the FEA was found to be $0.25 \mathrm{Rb}$ for the $1.21 \mathrm{~mm} \mathrm{A1008}$ steel plate with a $20 \mathrm{~g}$ charge, as compared to the experimental limit which lies between $0.38-0.53 \mathrm{Rb}$. For the $0.76 \mathrm{~mm}$ A1008 steel plate with a $20 \mathrm{~g}$ charge, the FEA yielded only a marginally larger failure limit of $0.29 \mathrm{Rb}$, as compared to the experimental value between $0.5-0.63 \mathrm{Rb}$. Although the FEA shows the correct trend of increasing standoff failure limit with decreasing thickness, the dependence on thickness was much weaker than observed in the experimental results. At the experimental shock failure standoffs, the LIC rupture ratio is predicted to be in the range of $0.75-0.85$, whereas the QIC rupture ratio is lower, at $\sim 0.45-0.5$. For the A1008 plates, the model predicts the plates to be stronger than was found in the experiments.

For the $1.21 \mathrm{~mm} 350 \mathrm{WT}$ steel plates with a $20 \mathrm{~g}$ charge, the failure limit predicted was $0.8 \mathrm{Rb}$ and $0.3 \mathrm{Rb}$, using the LIC and QIC, respectively, as compared to the experimental value between $0.5-0.63 \mathrm{Rb}$. The increase in failure limit compared to the $1.21 \mathrm{~mm} \mathrm{A1008} \mathrm{steel} \mathrm{plate} \mathrm{was} \mathrm{due} \mathrm{entirely} \mathrm{to} \mathrm{the} \mathrm{lower} \mathrm{failure} \mathrm{strain}\left(\varepsilon_{u l t}\right)$ for the $350 \mathrm{WT}$ material, and correctly predicts the same trend as the experiments. The greater variability in the two models seems 


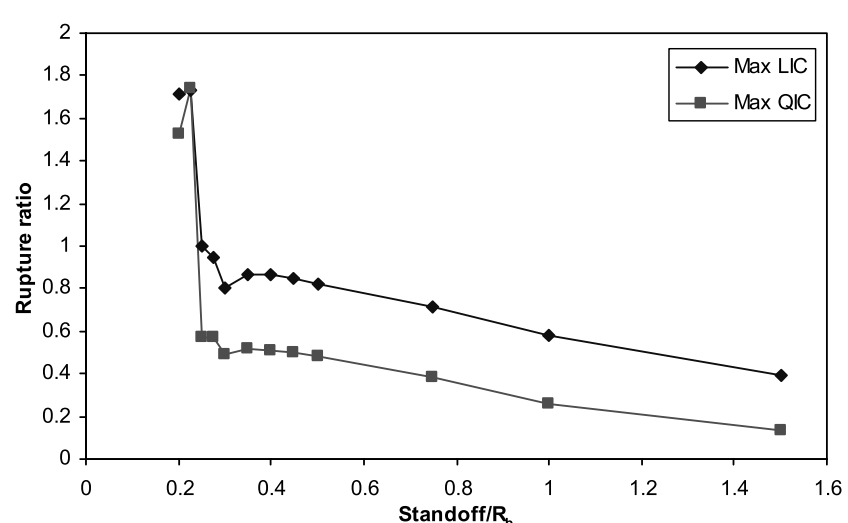

(a)

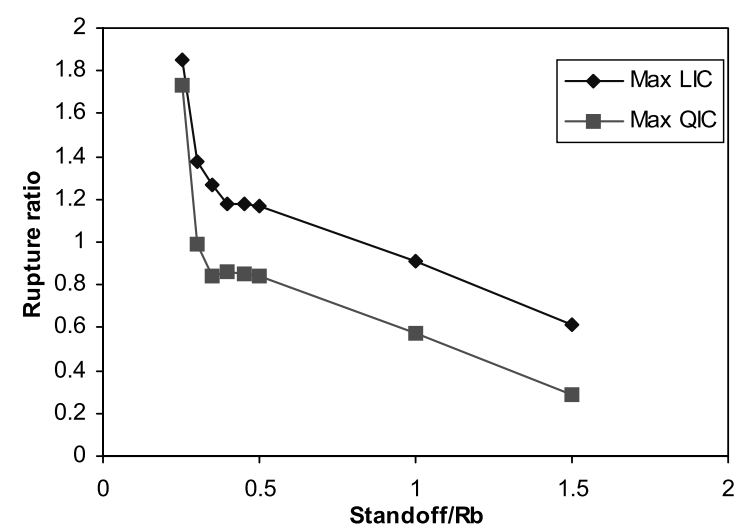

(b)

Fig. 10. Rupture ratios predict for $1.21 \mathrm{~mm}$ thick plates (a) A1008; (b) $350 \mathrm{WT}$.

to be related to the greater contribution of the membrane strain ratio to the failure, again due to the lower failure strain. At the experimental failure standoffs of $0.5-0.63 \mathrm{Rb}$, the LIC and QIC rupture ratios were $\sim 1.15$, and 0.85 respectively, which are clearly higher than what was predicted for the A1008 plates. Thus no single rupture ratio level can be made to apply to both plate materials.

Using three-dimensional solid elements for the plate targets should in principal give a better representation of the three-dimensional failure state that exists just prior to rupture, including the necking phenomenon. Additional improvements can be made by extending the plate model into the clamped region, which should allow the edge pull-in to be modelled with greater realism. Measurement of high-strain rate material properties is planned for use in future modelling efforts.

\section{Summary and conclusion}

In this study, the underwater explosive loading and failure of thin steel plates for close-proximity charges was investigated. The phenomenology of the UNDEX loading and the ensuing damage to a thin steel plate were observed. The shock and bubble jet loading on the plate surface was measured, showing the high-pressure, short duration pulse due to the shock with cavitation cutoff effects, and at a later time, the low-pressure, high-impulse pulse due to the bubble collapse, which was also affected by cavitation cutoff. These loading mechanisms contributed to producing three types of damage: holing with petaling, mode II or III edge rupture, and large deformation. By varying the charge standoff distance, four distinct regimes of failure standoff were identified: 1) holing due to contact or near-contact charges, 2) rupture due to shock only, 3) rupture due to shock and bubble jet, 4) deformation due to shock and bubble jet. As expected, the failure standoff limit increased as the plate thickness decreased. For 350WT steel, the failure standoff limit increased as compared to A1008 mild steel. The trends for shock failure were correctly reproduced by a simple FEA model using LIC and QIC failure criteria. Although the failure limit appeared to depend more strongly on the membrane strain ratio, a single rupture criterion could not be applied to the two steel types used in this study.

Future work will focus on a more detailed investigation of the mechanisms of plate failure, particularly with respect to edge effects such as plate slippage, and identifying sub-categories of failure modes in relation to the standoff failure regimes identified in the current work. Although the FEA performed in this study provides a relatively simple method of relating shock failure limits to the basic material properties of the plate, further work is necessary to improve the quantitative agreement and to account foe bubble jet loading (standoff regime 3). A promising approach may be to use an approach combining an Eulerian-Lagrangian mesh-coupling method [2,11,13] with the LIC or QIC rupture ratio criteria used in the Lagrangian FE model [10] for the plate. In this way, the loading model would capture the shock, bubble collapse, and cavitation processes, possibly resulting in improved predictions of the structural response and failure in all standoff regimes. Possible improvements to the modelling of the plate targets could also include three-dimensional element meshes and more realistic boundary constraints. 


\section{References}

[1] J.J. Lee, J. Gregson, G. Rude and G.T. Paulgaard, Underwater shock and bubble interactions from twin explosive charges, Proceedings of the 26th International Symposium on Shock Waves, July 15-20, 2007, Göttingen, Germany.

[2] E. Klaseboer, K.C. Hung, C. Wang, C.W. Wang, B.C. Khoo, P. Boyce, S. Debono and H. Charlier, Experimental and numerical investigation of the dynamics of an underwater explosion bubble near a resilient/rigid structure, J Fluid Mech 537 (2005), 387-413.

[3] R.H. Cole, 1948, "Underwater explosions", Princeton University Press.

[4] S.E. Menkes and H.J. Opat, Tearing and shear failures in explosively loaded clamped beams, Expl Mech 13 (1973), $480-486$.

[5] R.G. Teeling-Smith and C.N. Nurick, The deformation and tearing of thin circular plates subjected to impulsive loads, International Journal of Impact Engineering 11(1) (1991), 77-91.

[6] G.N. Nurick, M.E. Gelman and N.S. Marshall, Tearing of blast loaded plates with clamped boundary conditions, International Journal of Impact Engineering 18(7-8) (1996), 803-827.

[7] G.N. Nurick and G.C. Shave, The deformation and tearing of thin square plates subjected to impulsive loads - an experimental study, International Journal of Impact Engineering 18(1) (1996), 99-116.

[8] K. Ramajeyathilagam and C.P. Vendhan, Deformation and rupture of thin rectangular plates subjected to underwater shock, International Journal of Impact Engineering 30 (2004), 699-719.

[9] P. Church, M. Reynolds, W. Huntington-Thresher, R. Townsley and K. Sharpe, Underwater Plate Holing Studies, Proceedings of the 21st International Symposium on Ballistics, Adelaide, April 2004.

[10] M.J. Riley, G.T. Paulgaard, J.J. Lee and M.J. Smith, Failure Mode Transition in Air-backed Plates from Near Contact Underwater Explosions, Presented at the 79th SAVIAC, Orlando, FL, 2008.

[11] J. Gregson, T. Dunbar, J.J. Lee and R. Link, Simulation of structural failure from contact underwater explosions, Proceedings of the 78th SAVIAC, Philadelphia, PA, 2007.

[12] J.E. Slater, G. Rude and G.T. Paulgaard, Experimental study of air-backed and water-backed targets during near-contact explosions, DRDC Suffield Technical Report\# TR 2005-152, 2005.

[13] Z. Liu, W. Xie and Y.L. Young, Numerical modeling of complex interactions between underwater shocks and composite structures, Computational Mechanics 43(2) (2009), 239-251.

[14] N.S. Rudrapatna, R. Vaziri and M.D. Olson, Deformation and failure of blast-loaded square plates, International Journal of Impact Engineering 22 (1999), 449-467.

[15] G.T. Paulgaard, J.E. Slater and G. Rude, "Experimental Underwater Explosive Performance of C4", DRDC Suffield Contractor Report TR 2007-087, 2007.

[16] J.P. Best, On the dynamics of the bubble created upon detonation of a limpet mine, Defence Science and Technology Organization (Australia) report\# DSTO-TR-0439, 1996.

[17] M.E. Norwood and J. Gregson, Improvement and validation of the Trident UNDEX interface, DRDC Atlantic Contractor Report\#2006-155, 2005.

[18] J.A. DeRuntz, Enhanced analysis capability in USA-STAGS, Final report under contract N60921-840213, Lockheed Palo Alto Research Laboratory, 1986 

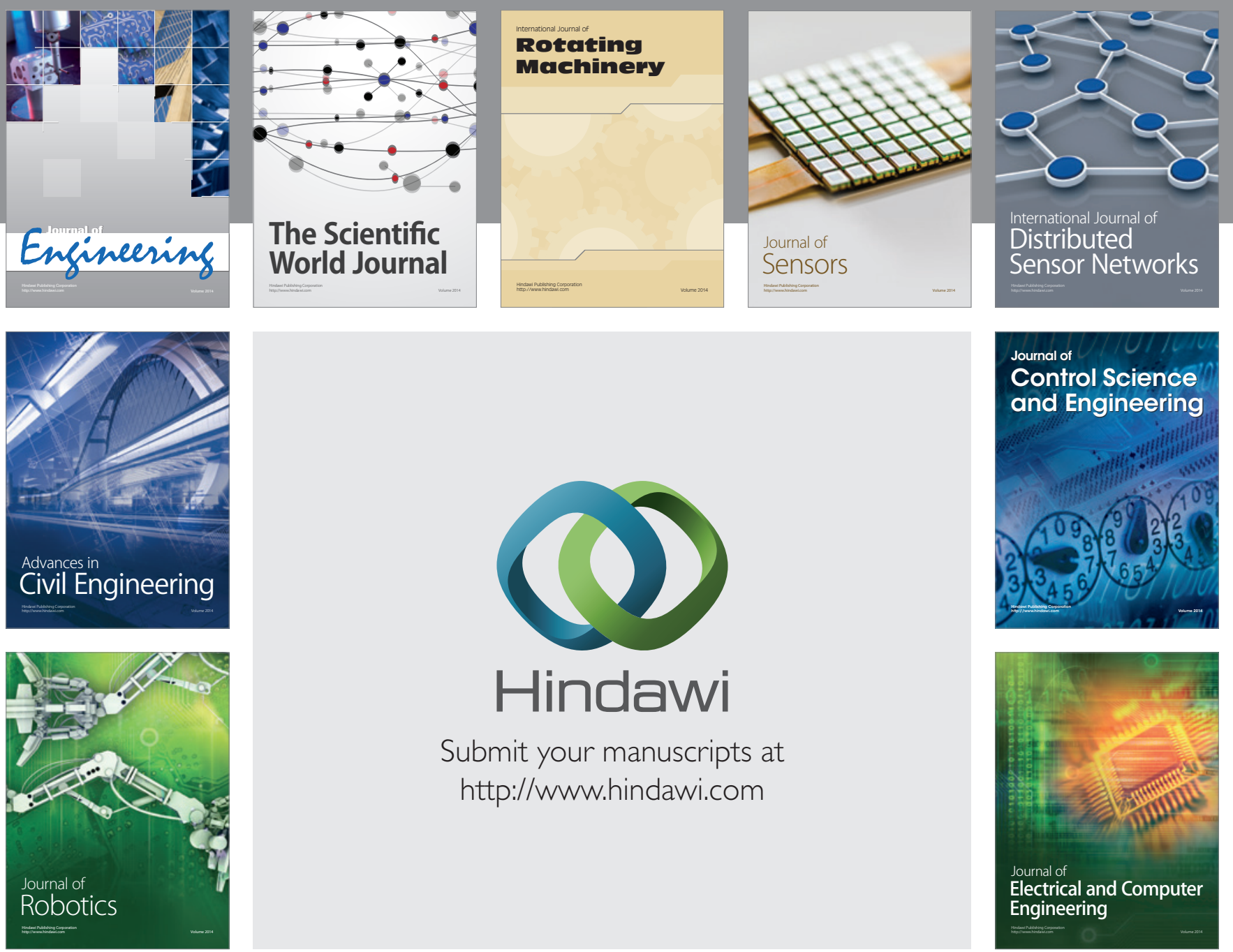

Submit your manuscripts at

http://www.hindawi.com
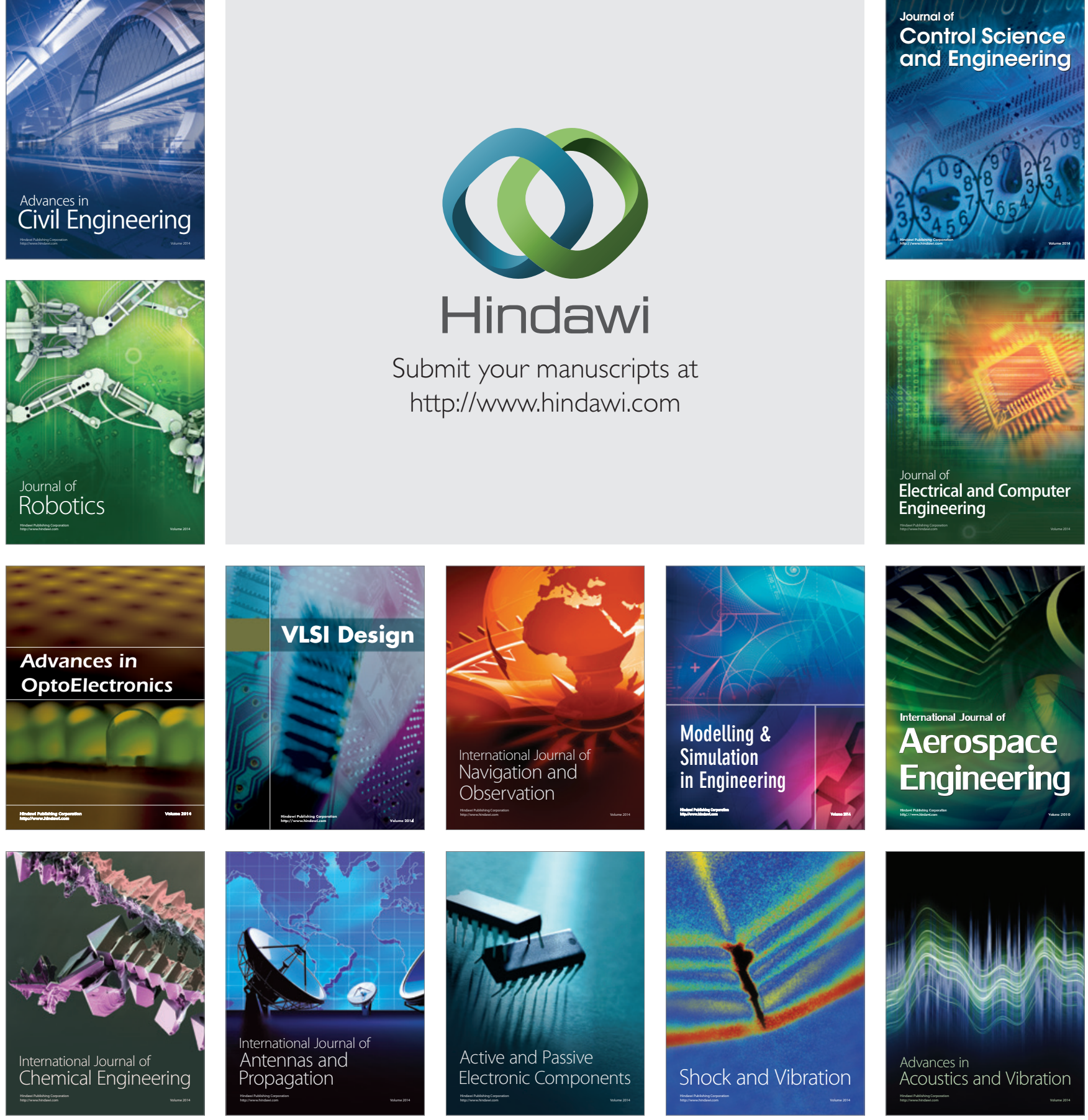